\title{
Outcome of tuberculosis treatment and its predictors among HIV infected patients in southwest Ethiopia
}

This article was published in the following Dove Press journal:

International Journal of General Medicine

6 June 2017

Number of times this article has been viewed

\author{
Adane Teshome Kefale \\ Yeniewa Kerie Anagaw \\ Department of Pharmacy, College \\ of Health Sciences, Mizan-Tepi \\ University, Mizan Aman, Ethiopia
}

Correspondence: Adane Teshome Kefale Department of Pharmacy, College of Health Sciences, Mizan-Tepi University, PO Box 260, Mizan Aman, Ethiopia Tel +25I 92 I465244 Email adanet20II@gmail.com
Background: Co-infection with HIV challenges treatment of tuberculosis (TB) and worsens the outcome. This study aimed to assess the outcome of TB treatment and its predictors among HIV infected patients at Mizan-Tepi University Teaching Hospital (MTUTH), Ethiopia.

Methods: Medical records of $188 \mathrm{~TB} / \mathrm{HIV}$ co-infected patients who attended the TB clinic of MTUTH from September 2012 to December 2015 were reviewed from March 14 to April 1, 2016. The primary endpoints of the study were treatment outcome of TB and its predictors. Data were analyzed by Statistical Package for Social Sciences version 21. Multivariable binary logistic regression analysis was carried out to identify predictors of treatment outcome. Statistical significance was considered at $p$-value $<0.05$.

Result: The treatment outcomes of TB patients included in this study were $18(9.57 \%)$ cured, 20 (10.64\%) defaulted, 24 (12.77\%) died, 39 (20.74\%) completed the treatment, and 87 (46.28\%) transferred out. A successful treatment outcome was achieved in 57 (30.32\%) patients. Initial World Health Organization (WHO) clinical stage III (COR: 2.60; 95\%CI: 1.17-5.76) and stage IV (COR: 4.00; 95\%CI: 1.29-12.40) were associated with unfavorable outcome. Both WHO stages (III, IV) at the time of HIV diagnosis were independent predictors of poor treatment outcome (AOR: 3.08; 95\%CI: 1.14-8.38; AOR: 5.80; 95\%CI: 1.36-24.71 respectively). However, smear positive TB was an independent predictor of a favorable treatment outcome (AOR: 2.50; 95\%CI: 1.13-5.51).

Conclusion: This study revealed that treatment outcome of TB patients was unsatisfactory, which signals a need for improved care. Advanced WHO clinical stages were predictors of poor outcome, while smear positive TB favors good outcome.

Keywords: TB treatment outcome, TB/HIV co-infection, MTUTH, Ethiopia

\section{Introduction}

Tuberculosis (TB) has a worldwide distribution, ${ }^{1}$ it is an airborne infection with high infectivity rate which is easily transmitted from person to person through droplets. ${ }^{2}$

In settings where TB and HIV are prevalent, patients enrolled for TB treatment can be grouped as HIV negative or HIV positive TB patients, based on their HIV serostatus. Anti-retroviral therapy (ART) can reduce the risk of TB associated death by $64 \%$ to $95 \%$. Owing to this benefit, ART should be commenced within 2-8 weeks after starting anti-TB treatment. ${ }^{3,4}$ HIV positive TB patients pose a challenge to TB treatment since they have a longer infectious period, and also poorer treatment outcome as compared with their HIV negative counterparts. ${ }^{5}$

The co-infection of TB and HIV exerts additive and bidirectional effects on each other. TB is one of the commonest opportunistic infections leading to increased 
morbidity and mortality in HIV infected patients. ${ }^{6}$ Likewise, infection with HIV is a known risk factor for TB infection and progression of latent infection to active disease. ${ }^{7} \mathrm{HIV}$ is associated with increased progression of latent TB by $20.6 \%-36.7 \%$ as compared with HIV negative people. ${ }^{8}$ In addition to increased risk of active TB disease following Mycobacterium tuberculosis infection at individual level, co-infection of HIV with TB also increases TB transmission rates at community level. ${ }^{9}$

$\mathrm{TB} / \mathrm{HIV}$ co-infection is a major public health challenge in low-income countries. TB is implicated for most deaths among HIV infected patients. ${ }^{10}$ Globally, nearly $10 \%$ of TB cases are HIV positive, and this figure reaches up to $30 \%$ in Africa countries. In sub-Saharan Africa, where Ethiopia is located, up to $80 \%$ of individuals with active TB disease are HIV positive. ${ }^{5}$

Ethiopia is one of the highly affected countries by TB/HIV co-infection; and ranked 7th among the 22 high TB burden countries in the world. ${ }^{11,12}$ The 2015 World Health Organization (WHO) global TB report estimated that, in Ethiopia, $15 \%-23 \%$ of TB patients tested for HIV were positive. ${ }^{12}$

TB treatment outcome is poor among HIV positive TB patients compared with HIV negative TB patients. ${ }^{13-17}$ There is a continuing need to routinely assess the likely reasons for poor treatment outcome among TB/HIV co-infected patients. This is particularly important in developing countries such as Ethiopia, where economic instability, low literacy level, and inadequate access to health care facilities might lead to the increased incidence of poor outcome. Treatment outcome is viewed as an important indicator of TB control programs, as suggested by WHO. ${ }^{12}$

Previous studies, conducted in different settings, reported variable results with respect to factors associated with unfavorable outcome of TB in HIV infected patients. The study conducted in India revealed that CD4 count $<200$ cells/ $\mu \mathrm{L}$ and retreated TB patients, as compared with new cases, were significantly associated with unfavorable outcome, while other sociodemographic and clinical characteristics were insignificant. ${ }^{18}$ Similarly, the study conducted in Northern Ethiopia showed that a CD4 count $<200$ cells/ $\mu \mathrm{L}$ was associated with unfavorable outcome. Besides, WHO clinical stage IV and age $>45$ years were predictors of unfavorable outcome. ${ }^{19}$ The study conducted in Northwest Ethiopia reported that being bedridden and experiencing anti-TB medication side effects were associated with treatment failure. ${ }^{20}$

Nevertheless, the issue of outcome of TB treatment and its predictors has not been well addressed in the study area.
Thus, the purpose of this study was to evaluate the treatment outcome of TB and associated factors among TB/HIV co-infected patients at Mizan-Tepi University Teaching Hospital (MTUTH), Ethiopia.

\section{Methods \\ Study setting}

The study was conducted at MTUTH, which is currently operated under Mizan-Tepi University. The hospital is located in Benchi Maji Zone, southwest of Ethiopia, and provides services to the residents of the zone and Gambella regional state. The hospital provides services in different departments; one of which is the TB clinic. The clinic registers and treats patients diagnosed with TB using "directly observed therapy" (DOT) strategy designed by the National Tuberculosis and Leprosy Control Program (NTLCP) of Ethiopia. ${ }^{11}$ The DOT strategy is implemented to enhance medication adherence and reduce subsequent drug resistance; hence, patients administer their medication under direct supervision of a health care provider. As per the state policy, the TB clinic provides the recommended medications for registered TB cases, screening for HIV serostatus, and referrals to ART clinic for HIV positive TB patients.

\section{Study design}

A retrospective cross-sectional study was conducted by reviewing a 42-month period (September 2012 to December 2015) of medical records of TB/HIV co-infected patients. The data were collected from March 14 to April 1, 2016. Patients with age $\geq 15$ years who had started and completed a course of anti-TB therapy or transferred during the study period were included in the study. All TB/HIV co-infected patients' medical records with complete information were reviewed to extract sociodemographic details of patients, TB type, medications given, and treatment outcome.

The exclusion criteria of the study were patients with incomplete medical records (ie, HIV status unknown, treatment outcome unknown), lost to follow-up, and patients transferred to MTUTH from other health facilities where their baseline data were not available.

\section{Data collection and statistical analysis}

A data collection checklist that contains sociodemographic characteristics, disease-related factors, medication-related factors, and treatment outcome was prepared to extract the data from patients' medical records. Data were collected by two nurses working at the TB clinic after being trained about the objectives of the study, data collection format, and techniques of data extraction. 
To ensure quality of data, the following measures were taken: data collectors were trained, and the extraction format was pretested using eight TB/HIV co-infected patient medical records at Tepi district hospital. In addition, principal investigators continuously supervised the whole data collection process and checked consistency and completeness of completed checklists daily.

The collected data were entered and analyzed using the Statistical Package for the Social Sciences 21.0 (IBM Corporation, Armonk, NY, USA). Descriptive statistics, such as frequency, percentage, mean, and standard deviation were used to summarize patients' baseline characteristics. Bivariate logistic regression was employed to identify independent variables that were candidates for multivariable logistic regression. Multivariable logistic regression model was fitted to determine independent predictors of treatment outcome when the $p$-value was $\leq 0.25$ on bivariate analysis. Statistical significance was considered when the $p$-value was $<0.05$.

\section{Definition of terms}

The following standard definitions of clinical case and treatment outcome of TB, adopted by the NTLCP guidelines ${ }^{11}$ and implemented in all health facilities in Ethiopia, were used for this research purpose.

\section{Case of TB}

A pulmonary TB case with one or more initial sputum smear examinations positive for acid-fast bacilli (AFB) or one in which a health worker has diagnosed TB and has decided to treat the patient with a full course of anti-TB treatment.

\section{Smear positive pulmonary TB (SPPTB)}

A patient with at least two initial sputum specimens positive for AFB by microscopy, or a patient with one initial sputum specimen positive for AFB by microscopy and positive culture, or a patient with one initial smear examination positive for AFB by direct microscopy and radiographic abnormalities consistent with active TB as determined by a clinician.

\section{Smear negative pulmonary TB (SNPTB)}

A patient with symptoms suggestive of TB, with at least three sputum specimens negative for AFB by microscopy, and with chest radiographic abnormalities consistent with active pulmonary TB, and lack of clinical response to 1 week of broad spectrum antibiotic therapy, or a patient whose diagnosis is based on culture positive M. tuberculosis but with three initial smear examinations negative by direct microscopy.

\section{Extrapulmonary TB (EPTB)}

TB in organs other than the lungs, proven by one culture positive specimen from an extrapulmonary site or histopathological evidence from a biopsy, or TB based on strong clinical evidence consistent with active EPTB and the decision by a clinician to treat with a full course of anti-TB therapy.

Patients with bacteriologically confirmed TB or diagnosed by a clinician were grouped based on the following case definitions using NTLCP guidelines. ${ }^{11}$

\section{New case $(\mathrm{N})$}

A patient who never had treatment for TB, or has been on anti-TB treatment for $<4$ weeks.

\section{Relapse (R)}

A patient declared cured or treatment completed of any form of TB in the past, but who reports back to the health service and is now found to be AFB smear positive or culture positive.

\section{Treatment after failure $(F)$}

A patient scheduled for retreatment due to positive smear or culture at the end of the 5 th month or later after commencing the previous treatment.

\section{Return after default (D)}

A patient previously recorded as a default from treatment who returns to the health facility with smear positive sputum results.

The following treatment outcome definitions were employed in all bacteriologically confirmed and clinically diagnosed TB cases. ${ }^{11}$

\section{Cured}

A patient whose sputum smear or culture was positive at the beginning of the treatment but who was smear or culture negative in the last month of treatment and on at least one previous occasion.

\section{Defaulter}

A patient who has been on treatment for at least 4 weeks and whose treatment was interrupted for 8 or more consecutive weeks.

\section{Died}

A patient who dies for any reason during the course of TB treatment. 


\section{Transfer out}

A patient who started treatment and has been transferred to another health facility and whose treatment outcome is unknown.

\section{Treatment completed}

A patient who completed anti-TB treatment without evidence of failure, but for whom sputum smear, culture results are not available in the last month of treatment and on at least one previous occasion.

\section{Treatment failure}

A patient whose sputum smear or culture is positive at 5 th month or later during treatment.

\section{Treatment success (favorable outcome)}

The sum of patients who are cured and those who have completed treatment.

\section{Unfavorable outcome (unsuccessful outcome)}

The sum of patients who are defaulter, died, transferred out, and patients with treatment failure.

\section{Ethical consideration}

The ethical clearance letter was obtained from Mizan-Tepi University, College of Health Sciences institutional review board, and taken to MTUTH clinical director, then the data were collected after obtaining permission from the Hospital director. Patient consent to review records was not necessitated by the ethics committee. The confidentiality of the data collected was always protected.

\section{Results}

\section{Sociodemographic characteristics of patients}

A total of 1740 TB adult patients' medical records at TB clinic of MTUTH from September 1, 2012 to December 31, 2015 were reviewed, of which 188 were TB/HIV co-infected. The prevalence of HIV among TB patients was $10.80 \%$. The HIV status of all TB patients was recorded. All TB/HIV coinfected patients fulfilled the inclusion criteria, hence, they were included in the final analysis. The mean age of participants was $30.55 \pm 8.96$ years. The baseline sociodemographic characteristics of study participants are summarized in Table 1.

\section{Clinical characteristics of participants}

Of the participants, 90 (47.87\%) patients were new HIV cases diagnosed with provider initiated counseling and testing at
Table I Demographic characteristics of TB patients co-infected with HIV at MTUTH, September 2012 to December 2015 $(\mathrm{N}=188)$

\begin{tabular}{|c|c|c|}
\hline Variables & Category & Frequency (\%) \\
\hline \multirow[t]{2}{*}{ Sex } & Male & $97(51.60)$ \\
\hline & Female & 91 (48.40) \\
\hline \multirow[t]{4}{*}{ Age group } & $15-29$ & 91 (48.40) \\
\hline & $30-44$ & $86(45.74)$ \\
\hline & $45-59$ & $9(4.79)$ \\
\hline & $\geq 60$ & $2(1.06)$ \\
\hline \multirow[t]{4}{*}{ Marital status } & Single & $67(35.64)$ \\
\hline & Married & 65 (34.57) \\
\hline & Divorced & $29(15.43)$ \\
\hline & Widowed & $27(14.36)$ \\
\hline \multirow[t]{4}{*}{ Educational status } & Illiterate & $52(27.66)$ \\
\hline & Primary & 70 (37.24) \\
\hline & Secondary & $59(31.38)$ \\
\hline & College & 7 (3.72) \\
\hline
\end{tabular}

the time of anti-TB treatment initiation. The remainder was previously diagnosed HIV patients, all of whom were on ART during TB diagnosis. All nevirapine-based regimens (in 36 patients) were changed to efavirenz at the commencement of TB treatment due to drug interaction. The majority of patients (67.6\%) had $<1$ year duration of HIV during TB diagnosis; with a mean duration of $1.38 \pm 2.02$ years. One hundred and sixty-three (86.71\%) patients were new TB cases, while two $(1.1 \%)$ cases were due to the failure of previous treatment (Table 2).

Of HIV-infected TB patients, $27(14.36 \%)$ had EPTB. The type of EPTB reported were TB lymphadenitis (14 cases), TB meningitis (10 cases), and TB spondylitis (3 cases). Among 188 TB/HIV co-infected patients, 44 (23.4\%) were WHO stage IV and 167 (88.8\%) patients had CD4 count $<350$ cells $/ \mathrm{mm}^{3}$ during TB diagnosis (Table 2). The median CD4 count during TB diagnosis was $193 \mathrm{cells} / \mathrm{mm}^{3}$ (interquartile range of 200). One hundred and seventy-one (91\%) patients received a combination of the standard four anti-TB drugs (rifampicin, isoniazid, ethambutol, pyrazinamide) on intensive phase, while 17 patients received five drugs (standard four drugs plus streptomycin).

\section{Treatment outcome and associated factors}

The overall treatment outcome of TB was $18(9.57 \%)$ cured, 39 (20.74\%) completed the treatment, 20 (10.64\%) defaulted, $24(12.77 \%)$ died, and 87 (46.28\%) transferred out. A high proportion of patients were transferred to other health facilities. The patients who were transferred were more likely to 
Table 2 Clinical characteristics of HIV infected TB patients at MTUTH, September 2012 to December $2015(\mathrm{~N}=188)$

\begin{tabular}{|c|c|c|}
\hline Variables & & $\mathbf{N}(\%)$ \\
\hline \multirow[t]{4}{*}{ TB case } & New & I63 (86.7I) \\
\hline & Relapse & $18(9.57)$ \\
\hline & Default & $5(2.66)$ \\
\hline & Treatment failure & $2(1.06)$ \\
\hline \multirow[t]{2}{*}{ Smear status } & Negative & $145(77.13)$ \\
\hline & Positive & $43(22.87)$ \\
\hline \multirow[t]{3}{*}{ TB type } & SNPTB & $118(62.77)$ \\
\hline & SPPTB & $43(22.87)$ \\
\hline & EPTB & $27(14.36)$ \\
\hline \multirow[t]{3}{*}{ CD4 counts at TB Dx } & $\leq 350$ & $167(88.83)$ \\
\hline & $350-500$ & $19(10.11)$ \\
\hline & $>500$ & $2(1.06)$ \\
\hline \multirow[t]{2}{*}{ WHO stage at TB Dx } & III & $144(76.60)$ \\
\hline & IV & $44(23.40)$ \\
\hline$A R T$ regimen during $T B$ & TDF/3TC/EFV & $152(80.85)$ \\
\hline treatment & AZT/3TC/EFV & $36(19.15)$ \\
\hline ART regimen at TB Dx & TDF/3TC/EFV & $38(38.78)$ \\
\hline \multirow[t]{3}{*}{$(\mathrm{N}=98)$} & $\mathrm{AZT} / 3 \mathrm{TC} / \mathrm{NVP}$ & $35(35.7 I)$ \\
\hline & AZT/3TC/EFV & $24(24.49)$ \\
\hline & TDF/3TC/NVP & $\mathrm{I}(\mathrm{I} .02)$ \\
\hline ART regimen change due & Yes & $36(19.15)$ \\
\hline to TB treatment $(\mathrm{N}=98)$ & No & $152(80.85)$ \\
\hline \multirow[t]{2}{*}{ Anti-TB regimen } & RHZE & I7I (90.96) \\
\hline & RHZES & $17(9.04)$ \\
\hline \multirow[t]{2}{*}{ History of TB treatment } & Yes & $25(13.30)$ \\
\hline & No & $163(86.70)$ \\
\hline \multirow[t]{3}{*}{ Duration of RVI in years } & $<1$ & $127(67.60)$ \\
\hline & $1-5$ & $48(25.50)$ \\
\hline & $>5$ & $13(6.90)$ \\
\hline
\end{tabular}

Abbreviations: 3TC, lamivudine; ART, anti-retroviral therapy; AZT, zidovudine; Dx, diagnosis; EFV, efavirenz; EPTB, extrapulmonary tuberculosis; MTUTH, MizanTepi University Teaching Hospital; NVP, nevirapine; RHZES, rifampin, isoniazid, pyrazinamide, ethambutol/streptomycin; RVI, retroviral infection; SNPTB, smear negative pulmonary tuberculosis; SPPTB, smear positive pulmonary tuberculosis; TB, tuberculosis; TDF, tenofovir disoproxil fumarate; WHO, World Health Organization.

be WHO stage III at the time of HIV diagnosis ( $p=0.043$ ) than those patients with other outcome variables. In terms of other sociodemographic and clinical characteristics, there was no statistically significant difference between transferred patients and patients with other outcome types. Treatment failure was not reported among the study participants during the review period (Table 3).

A successful treatment outcome was achieved in 57 $(30.3 \%)$ cases. Among sociodemographic and clinical characteristics, WHO stage at the time of HIV diagnosis, duration of HIV until TB diagnosis, and ART regimen change during TB treatment were associated with TB treatment outcome. Accordingly, patients with initial WHO stage III (COR: 2.60 ; 95\%CI: 1.17-5.76) and IV (COR: 4.00 ; 95\%CI: 1.29-12.40) were significantly associated with poor treatment outcome as compared with stage II. However, patients with HIV duration $>5$ years at the time of TB diagnosis were positively associated with successful TB treatment outcome as compared with $<1$ year (COR: 0.31 ; 95\%CI: 0.10-0.99). Similarly, patients whose initial regimen was changed due to TB treatment were associated with favorable treatment outcome (COR: 0.46; 95\%CI: 0.22-0.98) (Table 4). There was no statistically significant difference between treatment outcome with anti-TB regimen $(p=0.52)$ and ART regimen during TB treatment $(p=0.44)$.

Multivariable logistic regression output showed that smear status, TB type, and initial WHO stage were independent predictors of TB treatment outcome. Accordingly, patients with initial WHO stage III had a three times more unfavorable TB treatment outcome (AOR: 3.08; 95\%CI: 1.14-8.38), while WHO stage IV patients were approximately six times more likely to have a poor treatment outcome (AOR: 5.80; 95\%CI: 1.36-24.71) as compared with their WHO stage II counterparts. However, smear positive TB patients were 2.5 times more likely to have a good treatment outcome as compared with smear negative patients (AOR: 2.50; 95\%CI: 1.13-5.51). Similarly, SPPTB patients had a favorable success rate (AOR: 0.40; 95\%CI: $0.18-0.88$ ) in comparison with SNPTB.

Excluding transferred out patients from factor analysis, only initial WHO stage at the time of HIV diagnosis remained an independent predictor of unfavorable outcome. Accordingly, patients with initial WHO stage IV were 12 times more likely to have a poor outcome as compared with initial WHO stage II patients (AOR: 12.08; 95\%CI: 1.88-77.71).

\section{Discussion}

HIV infection of TB patients is considered a major public health problem, particularly in resource constrained settings like Ethiopia. This study found that the prevalence of HIV co-infection among TB patients was $10.8 \%$, which is lower as compared with the prevalence at country level $(15 \%),{ }^{12}$ and previous studies conducted in different areas: Ethiopia $(13.4 \%),{ }^{21}$ Brazil (19\%), ${ }^{22}$ and Nigeria $(42.7 \%) .{ }^{14}$ However, this finding is almost similar to the Northwest Ethiopian study $(10.9 \%){ }^{23}$

Poor treatment outcomes in our study, including "defaulted" (10.6\%) and "died" (12.8\%), were higher than reported in previous studies. The overall default rate in the current study was almost comparable to $8.1 \%$ in India $^{18}$ and $9 \%$ in Nigeria ${ }^{24}$ reported among HIV infected TB patients. The default rate in this study is more eminent than the average $(6.20 \%)$ noted among all TB cases in the 22 high-burden countries, ${ }^{25}$ but lower than the survey done 
Table 3 Treatment outcomes of HIV infected TB patients at MTUTH, September 2012 to December 2015 (N=I88)

\begin{tabular}{|c|c|c|c|c|c|c|c|}
\hline \multirow[t]{2}{*}{ Variables } & & \multicolumn{5}{|c|}{ TB treatment outcome } & \multirow{2}{*}{$\begin{array}{l}\text { Total } \\
\mathbf{N}(\%)\end{array}$} \\
\hline & & $\begin{array}{l}\text { Cured } \\
\text { N (\%) }\end{array}$ & $\begin{array}{l}\text { Defaulted } \\
\text { N (\%) }\end{array}$ & $\begin{array}{l}\text { Treatment } \\
\text { completed, N (\%) }\end{array}$ & $\begin{array}{l}\text { Died } \\
\text { N (\%) }\end{array}$ & $\begin{array}{l}\text { Transferred, } \\
\text { N (\%) }\end{array}$ & \\
\hline \multirow[t]{2}{*}{ Sex } & Male & II (5.9) & $10(5.3)$ & $17(9.0)$ & II (5.9) & $48(25.5)$ & $97(5 \mathrm{I} .6)$ \\
\hline & Female & $7(3.7)$ & $10(5.3)$ & $22(11.7)$ & $13(6.9)$ & $39(20.7)$ & 91 (48.4) \\
\hline \multirow[t]{4}{*}{ Age group } & $15-29$ & $6(3.2)$ & $8(4.3)$ & $18(9.6)$ & $15(8.0)$ & $44(23.4)$ & 91 (48.4) \\
\hline & $30-44$ & II (5.9) & II (5.9) & $18(9.6)$ & $7(3.7)$ & $39(20.7)$ & $86(45.7)$ \\
\hline & $45-59$ & $\mathrm{I}(0.5)$ & $\mathrm{I}(0.5)$ & $3(1.6)$ & $\mathrm{I}(0.5)$ & $3(1.6)$ & $9(4.8)$ \\
\hline & $\geq 60$ & $0(0.0)$ & $0(0.0)$ & $0(0.0)$ & $\mathrm{I}(0.5)$ & $\mathrm{I}(0.5)$ & $2(1.1)$ \\
\hline \multirow[t]{4}{*}{ Marital status } & Single & $5(2.7)$ & $4(2.1)$ & $12(6.4)$ & $10(5.3)$ & $36(19.1)$ & $67(35.6)$ \\
\hline & Married & $7(3.7)$ & $10(5.3)$ & $15(8.0)$ & $9(4.8)$ & $24(12.8)$ & $65(34.6)$ \\
\hline & Widowed & $3(1.6)$ & $3(1.6)$ & $4(2.1)$ & $4(2.1)$ & $13(6.9)$ & $27(14.4)$ \\
\hline & Divorced & $3(1.6)$ & $3(1.6)$ & $8(4.3)$ & $\mathrm{I}(0.5)$ & $14(7.4)$ & $29(15.4)$ \\
\hline \multirow[t]{4}{*}{ Educational level } & Illiterate & $8(4.3)$ & $3(1.6)$ & $10(5.3)$ & $9(4.8)$ & $22(11.7)$ & $52(27.7)$ \\
\hline & Primary & $7(3.7)$ & $9(4.8)$ & $13(6.9)$ & $9(4.8)$ & $32(17.0)$ & $70(37.2)$ \\
\hline & Secondary & $3(1.6)$ & $7(3.7)$ & $15(8.0)$ & $6(3.2)$ & $28(14.9)$ & $59(31.4)$ \\
\hline & College & $0(0.0)$ & I (0.5) & I (0.5) & $0(0)$ & $5(2.7)$ & $7(3.7)$ \\
\hline \multirow[t]{3}{*}{ TB Type } & SNPTB & $0(0.0)$ & $14(7.4)$ & $32(17.0)$ & $17(9.0)$ & $55(29.3)$ & $118(62.8)$ \\
\hline & SPPTB & $18(9.6)$ & $5(2.7)$ & $0(0.0)$ & $4(2.1)$ & $16(8.5)$ & $43(22.9)$ \\
\hline & EPTB & $0(0.0)$ & I (0.5) & $7(3.7)$ & $3(1.6)$ & $16(8.5)$ & $27(14.4)$ \\
\hline \multirow[t]{4}{*}{ TB case } & New & $17(9.0)$ & $16(8.5)$ & $35(18.6)$ & $21(11.2)$ & $74(39.4)$ & $163(86.7)$ \\
\hline & Relapse & I $(0.5)$ & $2(1.1)$ & $4(2.1)$ & $3(1.6)$ & $8(4.3)$ & $18(9.6)$ \\
\hline & After failure & $0(0.0)$ & $\mathrm{I}(0.5)$ & $0(0.0)$ & $0(0.0)$ & $\mathrm{I}(0.5)$ & $2(1.1)$ \\
\hline & Default & $0(0.0)$ & I (0.5) & $0(0.0)$ & $0(0.0)$ & $4(2.1)$ & $5(2.7)$ \\
\hline \multirow[t]{2}{*}{$\mathrm{Hx}$ of $\mathrm{TB}$ treatment } & Yes & $17(9.0)$ & $16(8.5)$ & $34(18.1)$ & $21(11.2)$ & $75(39.9)$ & $163(86.7)$ \\
\hline & No & I $(0.5)$ & $4(2.1)$ & $5(2.7)$ & $3(1.6)$ & $12(6.4)$ & $25(13.3)$ \\
\hline \multirow[t]{3}{*}{ CD4 count at TB Dx } & $<350$ & $17(9.0)$ & $19(10.1)$ & $32(17.0)$ & $24(12.8)$ & $75(39.9)$ & $167(88.8)$ \\
\hline & $350-500$ & I $(0.5)$ & $\mathrm{I}(0.5)$ & $6(3.2)$ & $0(0.0)$ & II (5.9) & $19(10.1)$ \\
\hline & $>500$ & $0(0.0)$ & $0(0.0)$ & $\mathrm{I}(0.5)$ & $0(0.0)$ & I $(0.5)$ & $2(1.1)$ \\
\hline \multirow[t]{2}{*}{ WHO stage at TB Dx } & III & $13(6.9)$ & $16(8.5)$ & $33(17.6)$ & $10(5.3)$ & $72(38.3)$ & $144(76.6)$ \\
\hline & IV & $5(2.7)$ & $4(2.1)$ & $6(3.2)$ & $14(7.4)$ & $15(8.0)$ & $44(23.4)$ \\
\hline \multirow[t]{2}{*}{ Anti-TB regimen } & RHZE & $17(9.0)$ & $17(9.0)$ & $36(19.2)$ & $21(11.2)$ & $80(42.6)$ & $|7|(9 \mid .0)$ \\
\hline & RHZES & I $(0.5)$ & $3(1.6)$ & $3(1.6)$ & $3(1.6)$ & $7(3.7)$ & $17(9.0)$ \\
\hline Total & & $18(9.6)$ & $20(10.6)$ & $39(20.7)$ & $24(12.8)$ & $87(46.3)$ & $188(100.0)$ \\
\hline
\end{tabular}

Abbreviations: Dx, diagnosis; EPTB, extrapulmonary tuberculosis; Hx, history; MTUTH, Mizan-Tepi University Teaching Hospital; RHZE, rifampin, isoniazid, pyrazinamide, ethambutol; RHZES, rifampin, isoniazid, pyrazinamide, ethambutol/streptomycin; SNPTB, smear negative pulmonary tuberculosis; SPPTB, smear positive pulmonary tuberculosis; TB, tuberculosis; WHO, World Health Organization.

in Gambella Regional Hospital in Ethiopia $(22.9 \%)^{26}$ and Nigeria $(38.6 \%) .{ }^{14}$ The difference in default rates in the study area might be due to the valuable effect of DOT, an increase in patients' awareness of infectious diseases and treatment adherence, and expansions of health institutions in the country, which can minimize dropout rate.

Worldwide, the segment of TB patients who died during treatment remained more than three times higher among HIV positive TB patients ( $11 \%$ vs $3.5 \%$ ) than HIV negative TB patients. Despite this figure being lower in the African Region, HIV positive TB patients were still almost twice as likely to die compared with HIV negative TB patients $(9.8 \%$ vs $5.1 \%){ }^{12}$ According to the result of our study, the mortality rate among the participants was $12.8 \%$, which is slightly higher than global and African data. The high rate of mortality in this study might be partly due to improper selection of anti-TB medication in patients who had a prior history of TB treatment where a five-drug combination must be used, ${ }^{11}$ while in the study area among patients who were candidates for rifampicin, isoniazid, ethambutol, pyrazinamide, and streptomycin, five patients received rifampicin, isoniazid, ethambutol, and pyrazinamide instead. Previously conducted studies showed varying results with regard to mortality of TB/HIV co-infected patients, ranging from $1.8 \%$ to $29 \% .{ }^{14-16,18,23,27}$ Mortality is different with geographical location and the year at which the studies were conducted. This variability is attributed to difference in TB care in different areas and improvement of care over the years.

Successful treatment was achieved only in $30.3 \%$ of all cases of TB. This result is unsatisfactory when compared with the WHO report, where $73 \%$ of TB/HIV co-infected patients globally, and $75 \%$ in Africa achieved successful 
Table 4 Factors associated with treatment outcome of TB in TB/HIV co-infected patients at MTUTH, September 2012 to December 2015

\begin{tabular}{|c|c|c|c|c|c|c|c|}
\hline \multirow[t]{2}{*}{ Variables } & & \multicolumn{2}{|c|}{ Treatment success rate } & \multicolumn{2}{|c|}{ Univariate analysis } & \multicolumn{2}{|c|}{ Multivariable analysis } \\
\hline & & Unsuccessful & Successful & $p$-value & COR $(95 \% \mathrm{Cl})$ & p-value & AOR (95\%Cl) \\
\hline \multirow[t]{2}{*}{ Sex } & Male & 69 & 28 & 1.00 & 1.00 & & \\
\hline & Female & 62 & 29 & 0.66 & $0.87(0.47,1.62)$ & & \\
\hline \multirow[t]{5}{*}{ Age group } & $15-29$ & 67 & 24 & 1.00 & 1.00 & & \\
\hline & $30-44$ & 57 & 29 & 0.29 & $0.70(0.37,1.34)$ & & \\
\hline & $45-59$ & 5 & 4 & 0.26 & $0.448(0.1 \mathrm{I}, \mathrm{I} .8 \mathrm{I})$ & & \\
\hline & $\geq 60$ & 2 & 0 & 0.99 & 546410616 & & \\
\hline & & & & & $(0.00,--)$ & & \\
\hline \multirow[t]{4}{*}{ Education } & Illiterate & 34 & 18 & 0.30 & $0.31(0.04,2.82)$ & & \\
\hline & Primary & 50 & 20 & 0.43 & $0.42(0.05,3.68)$ & & \\
\hline & Secondary & 41 & 18 & 0.39 & $0.38(0.04,3.37)$ & & \\
\hline & College & 6 & 1 & 1.00 & 1.00 & & \\
\hline \multirow[t]{4}{*}{ Marital status } & Single & 50 & 17 & 1.00 & 1.00 & 1.00 & 1.00 \\
\hline & Married & 43 & 22 & 0.29 & $0.66(0.3 \mathrm{I}, \mathrm{I} .4 \mathrm{I})$ & 0.14 & $0.54(0.24,1.22)$ \\
\hline & Widowed & 20 & 7 & 0.96 & $0.97(0.35,2.70)$ & 0.96 & $0.97(0.332,2.84)$ \\
\hline & Divorced & 18 & 11 & 0.22 & $0.56(0.22, I .4 I)$ & 0.27 & $0.57(0.2 \mathrm{I}, \mathrm{I} .55)$ \\
\hline \multirow[t]{2}{*}{ Smear status } & Positive & 25 & 18 & 0.06 & $0.51(0.25,1.04)$ & 0.02 & $0.40(0.18,0.88)$ \\
\hline & Negative & 106 & 39 & 1.00 & 1.00 & 1.00 & 1.00 \\
\hline \multirow[t]{3}{*}{ TB type } & SNPTB & 86 & 32 & 1.00 & 1.00 & 1.00 & 1.00 \\
\hline & SPPTB & 25 & 18 & 0.08 & $0.52(0.25,1.07)$ & 0.02 & $0.40(0.18,0.88)$ \\
\hline & EPTB & 20 & 7 & 0.90 & $1.06(0.4 \mathrm{I}, 2.75)$ & 0.70 & $0.82(0.30,2.27)$ \\
\hline \multirow[t]{2}{*}{ WHO stage at TB Dx } & III & 98 & 46 & 1.00 & 1.00 & & \\
\hline & IV & 33 & 11 & 0.38 & I.4I $(0.65,3.03)$ & & \\
\hline \multirow[t]{3}{*}{ Initial WHO stage } & II & 16 & 16 & 1.00 & 1.00 & 1.00 & 1.00 \\
\hline & III & 91 & 35 & 0.02 & $2.60(1.17,5.76)$ & 0.03 & $3.08(1.14,8.38)$ \\
\hline & IV & 24 & 6 & 0.02 & $4.00(1.29,12.42)$ & 0.02 & $5.80(1.36,24.7 I)$ \\
\hline Duration of RVI at TB Dx in & $<1$ & 93 & 34 & 1.00 & 1.00 & 1.00 & 1.00 \\
\hline \multirow[t]{2}{*}{ years } & $1-5$ & 32 & 16 & 0.39 & $0.73(0.36,1.50)$ & 0.66 & $1.23(0.49,3.07)$ \\
\hline & $>5$ & 6 & 7 & 0.05 & $0.31(0.10,0.99)$ & 0.34 & $0.52(0.14,2.00)$ \\
\hline \multirow[t]{3}{*}{ CD4 count at ART initiation } & $<200$ & 54 & 18 & 1.00 & 1.00 & 1.00 & 1.00 \\
\hline & $200-350$ & 50 & 21 & 0.54 & $0.79(0.38,1.66)$ & 0.87 & $1.07(0.47,2.42)$ \\
\hline & $>350$ & 27 & 18 & 0.09 & $0.50(0.22, \mathrm{I} . \mathrm{II})$ & 0.79 & $0.88(0.35,2.25)$ \\
\hline \multirow[t]{2}{*}{ ART changed } & Yes & 20 & 16 & 1.00 & 1.00 & 1.00 & 1.00 \\
\hline & No & $\mathrm{III}$ & 41 & 0.04 & $2.17(1.02,4.58)$ & 0.31 & $1.62(0.635,4.12)$ \\
\hline \multirow[t]{3}{*}{ CD4 count at TB Dx } & $<350$ & 118 & 49 & 1.00 & 1.00 & & \\
\hline & $350-500$ & 12 & 7 & 0.50 & $0.71(0.26,1.92)$ & & \\
\hline & $>500$ & $\mathrm{I}$ & 1 & 0.54 & $0.42(0.02,6.77)$ & & \\
\hline
\end{tabular}

Abbreviations: ART, anti-retroviral therapy; Dx; diagnosis; EPTB, extrapulmonary tuberculosis; MTUTH, Mizan-Tepi University Teaching Hospital; RVI, retroviral infection; SNPTB, smear negative pulmonary tuberculosis; SPPTB, smear positive pulmonary tuberculosis; TB, tuberculosis; WHO, World Health Organization.

treatment. ${ }^{12}$ The success rate of this study is a lot lower than previous works in resource limited countries. ${ }^{14-16,18}$ The low rate of successful treatment outcomes found in our study might be partly due to the high rate of transferred patients $(46.3 \%)$, where treatment outcomes of those patients were not recorded in the facility where they started the treatment. Since the hospital is a referral center for other institutions in the vicinity, patients who were diagnosed or admitted in hospital were transferred to their nearest health facility after completing the intensive phase, where the outcome could not be determined at this time.

Patients with advanced immunosuppression, WHO stage III and IV during initial diagnosis of HIV, were linked with increased risk of unfavorable treatment outcome, consistent with the literature. ${ }^{14,19,28}$ Patients with advanced disease might be faced with multiple opportunistic infections and low CD4 count which directly affect TB treatment outcome. However, smear positive status was an independent predictor of successful treatment outcome which was also reported in Nigeria. ${ }^{29}$ Patients with smear positive results might have enough immunity to fight the infection, which enhances favorable TB treatment outcome.

The major limitation of this work is the use of retrospective secondary data, which is totally restricted to whatever is documented in the TB registers. Predictor variables which might affect outcome like treatment adherence level, comorbidities, 
other opportunistic infections as well as behavioral and social factors, were not recorded. In addition, follow-up smear status (2nd month) was not recorded in the chart. Moreover, many patients were transferred to other health facilities where it is difficult to track what happened thereafter. As per WHO definition, those patients transferred were included under unfavorable outcome, but it does not necessarily mean that they died or failed treatment after being transferred.

\section{Conclusion}

This study revealed that treatment outcome of TB in TB/ HIV co-infected patients was significantly low. Mortality and default rates were high in the study area, which signals the need to improve counseling regarding medication adherence, and health education to reduce treatment interruption. Advanced clinical WHO stage of HIV is an independent predictor of poor treatment outcome. Hence, early initiation of ART can facilitate immunologic recovery and subsequent improvement of treatment outcome

\section{Disclosure}

The authors report no conflicts of interest in this work.

\section{References}

1. Lucas AO, Gilles MH. Short textbook of public health medicine for the tropics. $4^{\text {th }}$ ed. London: Edward Arnold; 2003.

2. Parks K. Textbook of preventive and social medicine. $23^{\text {rd }}$ ed. India: MIS Banarsidas Bhand; 2015.

3. Lawn SD, Myer L, Edwards D, Bekker L, Wood R. Short-term and long-term risk of tuberculosis associated with $\mathrm{CD} 4$ cell recovery during antiretroviral therapy in South Africa. AIDS. 2009:23 (13):1717-1725.

4. Abdool Karim SS, Naidoo K, Grobler A, et al. Integration of antiretroviral therapy with tuberculosis treatment. $N$ Engl J Med. 2011;365(16): 1492-1501.

5. World Health Organization. TB/HIV: a clinical manual. $2^{\text {nd }}$ ed. Geneva: WHO; 2004. Available from: http://www.who.int/tb/publications/ who_htm_tb_2004_329/en/.Accessed May 15, 2017.

6. Corbett EL, Watt CJ, Walker N, et al. The growing burden of tuberculosis: global trends and interactions with the HIV epidemic. Arch Intern Med. 2003;163 (9):1009-1021.

7. Pawlowski A, Jansson M, Skold M, Rottenberg ME, Kallenius G. Tuberculosis and HIV co-infection. PLoS Pathog. 2012;8 (2):e1002464.

8. Kassaye SG, Levy V. Fundamentals of global HIV medicine. Temesgen Z, editor. Atlanta: IHL press; 2009.

9. Odhiambo JA, Borgdorff MW, Kiambih FM, et al. Tuberculosis and the HIV epidemic: increasing annual risk of infection in Kenya, 1986-1996. Am J Public Health. 1999:89 (7): 1078-1082.

10. Gandhi NR, Moll AP, Lalloo U, et al. Successful integration of tuberculosis and HIV treatment in rural South Africa: the Sizonq'oba study. J Acquir Immune Defic Syndr. 2009;50 (1):37-43

11. Federal Ministry of Health of Ethiopia. Tuberculosis, leprosy and TB/ $H I V$ prevention and control program manual 4th ed. 2008. Available from: http://www.who.int/hiv/pub/guidelines/ethiopia_tb.pdf. Accessed on May $25,2017$.
12. World Health Organization. Global Tuberculosis report, 2015. Geneva: WHO. Available from: http://apps.who.int/iris/bitstream/ 10665/191102/1/9789241565059_eng.pdf. Accessed May 15, 2017.

13. World Health Organization. Global Tuberculosis report, 2013. Geneva: WHO. Available from: http://apps.who.int/iris/bitstr eam/10665/91355/1/9789241564656_eng.pdf. Accessed May 24, 2017.

14. Ofoegbu OS, Odume BB. Treatment outcome of tuberculosis patients at National Hospital Abuja Nigeria: a five year retrospective study. S Afr Fam Pract. 2015;57 (1):50-56.

15. Tweya H, Feldacker C, Phiri S, et al. Comparison of treatment outcomes of new smear-positive pulmonary tuberculosis patients by HIV and antiretroviral status in a TB/HIV clinic, Malawi. PLoS One. 2013;8 (2):e56248.

16. Ali AS, Mavundla TR, Fantu R, Awoke T. Outcomes of TB treatment in HIV co-infected TB patients in Ethiopia: a cross-sectional analytic study. BMC Infect Dis. 2016;16 (1):640.

17. Gebremariam G, Asmamaw G, Hussen M, et al. Impact of HIV status on treatment outcome of tuberculosis patients registered at Arsi Negele Health Center, Southern Ethiopia: a six year retrospective study. PLoS One. 2016;11 (4): $\mathrm{e} 0153239$.

18. Sharma SK, Soneja M, Prasad KT, Ranjan S. Clinical profile \& predictors of poor outcome of adult HIV-tuberculosis patients in a tertiary care centre in north India. Indian J Med Res. 2014;139 (1): 154-160.

19. Belayneh M, Giday K, Lemma H. Treatment outcome of human immunodeficiency virus and tuberculosis co-infected patients in Public hospitals of eastern and southern zone of Tigray region, Ethiopia. Braz $J$ Infect Dis. 2015;19 (1):47-51.

20. Sinshaw Y, Alemu S, Fekadu A, Gizachew M. Successful TB treatment outcome and its associated factors among TB/HIV co-infected patients attending Gondar University Referral Hospital, Northwest Ethiopia: an institution based cross-sectional study. BMC Infect Dis. 2017; 17 (1):132.

21. Biruk, Yimam B, Abrha H, Biruk S, Amdi FZ. Treatment outcomes of tuberculosis and associated factors in an Ethiopian University hospital. Advances in Public Health. 2016;(2016):8504629.

22. do Prado TN, Miranda AE, de Souza FM, et al. Factors associated with tuberculosis by HIV status in the Brazilian national surveillance system: a cross sectional study. BMC Infect Dis. 2014;14:415.

23. Beza MG, Wubie MT, Teferi MD, Getahun YS, Bogale SM, Tefera SB. A five years tuberculosis treatment outcome at Kolla Diba Health Center, Dembia District, Northwest Ethiopia: a retrospective cross-sectional analysis. J Infect Dis Ther. 2013;1:101.

24. Dauda MM. Evaluation of the efficacy of directly observed treatment short course (DOTS) in patients with tuberculosis and HIV co-infection in Kano, Nigeria. Rev Infect. 2010;1:218-223.

25. World Health Organization. Global Tuberculosis Control: Surveillance, Planning, Financing. Geneva: WHO; 2005. Available from: http://library.cphs.chula.ac.th/Ebooks/AnnualReport/TB/TB2005.pdf. Accessed May 25, 2017.

26. Demeke D, Legess M, Bati J. Trend of tuberculosis and treatment outcomes in Gambella region with special emphasize on Gambella Regional Hospital, Western Ethiopia. J Mycobact Dis. 2013;3:2.

27. Banerjee A, Moyos, Salaniponi F, Harries A. HIV testing and tuberculosis treatment outcome in a rural district in Malawi. Trans $R$ Soc Trop Med Hyg. 1997;91 (6):707-708.

28. Dheda K, Lampe FC, Johnson MA, Lipman MC. Outcome of HIVassociated tuberculosis in the era of highly active antiretroviral therapy. J Infect Dis. 2004;190 (9):1670-1676.

29. Ifebunandu NA, Ukwaja KN, Obi SN. Treatment outcome of HIVassociated tuberculosis in a resource-poor setting. Trop Doct. 2012;42 (2):74-76. 
The International Journal of General Medicine is an international, peer-reviewed open-access journal that focuses on general and internal medicine, pathogenesis, epidemiology, diagnosis, monitoring and treatment protocols. The journal is characterized by the rapid reporting of reviews, original research and clinical studies across all disease areas.
The manuscript management system is completely online and includes a very quick and fair peer-review system, which is all easy to use. Visit http://www.dovepress.com/testimonials.php to read real quotes from published authors. 